\title{
Building Bridges: The Modes of Architecture
}

\author{
Miriam Vieira
}

\section{Contents}

3.1 Assembling Foundations.......................................................................... 59

3.2 Setting Up the Piers, or the Modes of Architecture...................................... 63

3.3 Adding Girders: Embodiment and Perspective............................................ 66

3.4 The Deck, or Architecture's Medial Traits..................................................... 72

References............................................................................................. 75

\subsection{Assembling Foundations}

It is possible to explore the relationship between architecture and other media through a wide variety of theoretical scopes - from time-space relations, as described by Gaston Bachelard (1994 [1964]) and Stephanie Glaser $(2009,2014)$, to Ulf Pettersson's cognitive approach (2013), or even Jennifer Bloomer's philosophical one (1993). It is also possible to view the architect's activities or a piece of architecture from different angles. Although still not nearly as extensive as the field of research dealing with the relationship between literature and painting, investigations of literature and architecture have nonetheless become more common over

\section{Vieira $(\bowtie)$}

Universidade Federal de São João del Rei, São João del Rei, Brazil

(C) The Author(s) 2021

L. Elleström (ed.), Beyond Media Borders, Volume 2, https://doi.org/10.1007/978-3-030-49683-8_3 
recent decades. Departing from the premise that ekphrasis is meant to evoke an absent image in the mind of the spectator, or the reader, and thereby to provoke an emotional response, I have elsewhere studied such relations by using the notion of architectural ekphrasis as a theoretical operator, under the light of intermedial studies (Vieira 2016, 2020). While examining the possibilities for working with this typology, I realized that the already consolidated pictorial models' parameters were not sufficient for my needs. One of the greatest challenges I faced was the delimitation of architecture's medial traits that literature is actually able to transmediate. Lars Elleström's proposed model for studying the transfer of media characteristics was crucial to achieving consistent results $(2010,2020)$. The four modalities of media, along with their qualifying aspects, became the backbone of an interpretative model proposed to explore the presence of architecture in literature. The aim of this chapter is then to delve into the core of my research: the modality modes of architecture.

According to Mario Biselli, architecture is "the intersection between the hard sciences and humanism" (Biselli apud Penna 2005: np), while Gustavo Penna defines it as "the spacial synthesis of all culture"2 (Penna 2005: np). In order to establish which kind of architecture I mean to explore, I depart from its dictionary definition as the "art and technique of organizing spaces and creating environments to shelter the many kinds of human activities, aiming also at specific aesthetic intentions"3 (Houaiss and Villar 2009: 186), along with the premise that, in architecture, "the work of many individuals will be involved and transformed within the unity of the finished whole" (Crowther 2009: 182-183), where the "whole" is the building itself. Adopting a more philosophical point of view, Karsten Harries reflects upon the notion of architecture as an interpretive and critical act, as well as on the possibilities of viewing architectural works as "texts" (Harries 1997: 4). According to Harries, the style of a building, when attributed to a certain code, can communicate a "way of standing in the world, a specific ethos" (Harries 1997: 92). The French architect Émile Aillaud (1902-1988) has for his part argued that "architecture is nothing more than the organization of a story whose syntactical elements are constituted by a scenery that carries it". Aillaud explains that he himself has built "cities, and these cities are themselves operas, stories told; they are great stories in which one can dwell, an inhabitable story" (Aillaud apud Hamon 1992: 29, footnote 13). Based on Aillaud's reasoning, Philippe Hamon illustrates the important narrative capability of architects, "who on the one hand listen to the narrative instructions of their 
clients, and on the other hand produce places that are stories as well as stories that are places" (Hamon 1992: 29). As a qualified medium, architecture may, under specific contextual qualitative aspects, convey messages to society, such as power or status. With this idea in mind, I consider that the two-way narrative capability suggested by Hamon requires a refinement of the communicative tools used in interactions between the client, the architect, and other relevant professionals involved in the architectural process, in addition to the building's final users.

Considering how all media products necessarily have several media dimensions, Jørgen Bruhn uses the term medialities to discuss media as "specified clusters of communicative forms" (Bruhn 2016: 17) that "may be briefly defined as tools of communicative action inside or outside the arts" (1). Accordingly, in his treaty on the autopoiesis of architecture, Patrik Schumacher ${ }^{4}$ argues that architecture can and should be considered as a (qualified) medium (2010: 323-362). The author explains that "architects communicate to wider audiences via buildings and designed spaces. Buildings and spaces constitute a very specific type of communication: they are ordering and framing communications $[\ldots]$ between people co-present in space" (Schumacher 2011: 1). In other words, when understood as a process, architecture may be considered a medium due to its inherent potential to store communication. The concept of "process" is thus central to my previous investigation of architectural ekphrasis. ${ }^{5}$ Moreover, the communication between those involved (client, architect, engineer, technicians, construction workers, and others) in relation to the edifice's modality modes is key to the fulfillment of an architectural process.

Architecture, as a process, ${ }^{6}$ originates in a client's wish. And that wish must, before it can be consolidated into a palpable building, undergo a succession of stages carried out through sketches, technical drawings, mockups, models, and so forth. Such depictions operate in the same way as librettos in opera, musical scores in performance, or screenplays in film. As such, we understand that architecture is developed through a dynamic communicative process in which every stage is accomplished through specific qualified submedia (graphic and technical representations) that not only "crave" for transmediation but also operate as part of a predetermined hierarchical process. For instance, the client's desire is followed by the architect's interpretation of the oral verbalization of such wishes, expressed through sketches and technical drawings. However, as the architect Steen Eiler Rasmussen states, "not everyone [...] can visualize a 
building merely by looking at the plans" (Rasmussen 1964 [1959]: 9). Therefore, the inclusion of other submedia-such as models and technical representations - is made necessary to the process's successful culmination at the construction site, where the architectural work will in fact be executed.

According to Rasmussen, "the architect is a sort of theatrical producer, the man who plans the setting for our lives, $[\ldots]$ but his producer job is difficult for several reasons. First of all, the actors are quite ordinary people" (Rasmussen 1964: 10). In this sense, the submedia which structure the stages of the process "are not an end in themselves, a work of art, but simply a set of instructions, an aid to the craftsmen who construct his buildings" (Rasmussen 1964: 14). These stages can be roughly described as: (a) the verbalization of a client's desire; (b) the architect's mental interpretation of the client's intention; (c) the representation of this cognitive import through two-dimensional visual qualified submedia; ${ }^{7}$ (d) the graphic representation of the future edifice's volume, expressed by CG renderings or $3 \mathrm{D}$ models; ${ }^{8}$ (e) the qualified submedia known as a blueprint, comprised of plans, façades, and sections, technically and diagrammatically representing the architectural project; 9 (f) the construction site, in which the entire process will be transmediated, to finally culminate; $(\mathrm{g})$ in the building per se. All of the mentioned submedia-graphic, diagrammatic, and technical representations, such as sketches, plans, blueprints, mockups, CG renderings, and 3D models-are relevant within the chain of a communicative process containing different levels of technical and architectural literacy, where a considerable amount of verbal articulation may be required if any of the stages is not decoded in detail.

Once the understanding of architecture as a medium has been established, I believe it is useful to identify its intrinsic characteristics and affordances, which are the medial traits that may be transmediated by literature, more specifically, works of fiction in which architecture plays a significant role so that the full architectural experience can be unfolded in the reader's mind through words. Since I have previously identified that the already consolidated pictorial models' parameters are not enough for scrutinizing the relationship between these two media types-architecture and literature-the proposed model for the study of transfer of media characteristics among dissimilar media in this volume (Elleström 2020) was crucial for the delimitation of architecture's medial traits. Therefore, as this is a reductionist model, where there is nothing to remove, but certainly to 
expand from, the foundation of my analysis also counts on the notions of embodiment and perspective in order to broaden the understanding of the process in which architecture is transmediated by literature.

\subsection{Setting Up the Piers, or the Modes of Architecture}

As proposed by Elleström $(2010,2014,2018$ a, b, 2020), semiotic characteristics - which include iconic, indexical, and symbolic aspects-are combined with presemiotic ones - which speak to the fundaments of mediation by involving the material, sensorial, and spatiotemporal modalities and their respective contextual and operational qualifying aspects. Therefore, in order to investigate the four modalities of architecture, I depart from questioning the basics: (a) What is the dominant sign system in architecture? (b) What materials constitute architecture? (c) How can architecture be perceived by the senses? (d) What are the possible relationships between architecture, time, and space? (e) Under which historical, cultural, and social circumstances has the building been designed? (f) Which aesthetic movement has influenced the architectural process?

The semiotic modality deals with the system of media signification and representation; the representing and represented; and more specifically to my case study, the objects and different media products that act as signs in relation to one another. Thus, it is relevant to understand how iconicity is based on the similarities between the involved media types; indexicality on their contiguity; and symbolicity on pre-established habits and conventions (Elleström 2010, 2014, 2018a, b, 2020). The first premise, the structural similarity - or diagrammatic iconicity, according to Charles Sanders Pierce-between the style of the architectural work and the written text, is probably the most frequently studied, as for instance in the way that nineteenth-century English Gothic fiction borrowed elements from gothic medieval architecture. Hamon (1999) consistently shows examples of iconicity based on similarity in his work on the relations between architecture and nineteenth-century French literature. ${ }^{10}$ Regarding the architectural process stages that take place before the construction begins, the second premise relies on indexicality, whereas the habits and conventions suggested by the last premise will depend on the cultural background of those involved. Hence, architecture as a process is apt to prompt a communicative process by encompassing both visual and verbal signs, by 
means of sketches, plans, and models, as well as through the negotiations between client, architect, and all other professionals involved in the design project. Therefore, meaning is assigned through a combination of signs of equal importance, weight, and value within the architectural chain of semiosis.

An edifice is comprised of different materials, such as brick, cement, mortar, glass, and steel. However, the material modality concerns both the physical materiality and the mental relationship involved within its transmediation. Therefore, if architecture is to be understood as a process spanning several stages, materiality will also manifest itself inside the minds of those involved in said process, as discussed by cognitive studies. Architect Christian Norberg-Schulz (1980) relates the materiality of architecture to the linguistic structure employed in its procedural verbal negotiations. According to him, the structure of a place-be it a country, a landscape, or a building-includes the space itself, the characteristics of the manmade environment, and the respective technology employed in its execution. The author states that places tend to be designated by nouns, such as "island", "forest", or "street", as well as "wall", "roof", and "door", since instead of referring to "space" in our daily lives, we refer to the relationships between things which are, for example, "over", "in", or "along” one another. Space, therefore, if understood as a system of relationships, is indicated through prepositions and phrasal prepositions. The technology and the characteristics present in man-made environments are, in turn, indicated by adjectives (Norberg-Schulz 1980: 15-16). Norberg-Schulz's contribution is indeed useful in the linguistic analysis of architectural ekphrasis.

As a process, architecture comprises a series of stages between the decision of having something built to the actual usage of the edifice in which is created an interactive discourse between client(s), architect(s), and all others involved. Beyond the linguistic elements put forth by NorbergSchulz, this communication will only reach a common goal when a common cognitive import is incited among all parties. Although the process is conceived in the client's mind, its function will be triggered by the architect. This means that the transfer of vivid visions and perceptions by means of a shared mental image, which happens to be the rhetorical principle of ekphrasis, is highly relevant to its successful accomplishment.

According to Rudolf Arnheim, "a building, [...] in all its aspects is a fact of the human mind. It is an experience of the senses of sight and sound, of touch and heat and cold and muscular behavior, as well as the resultant 
thoughts and strivings" (Arnheim 1977: 4). Thus, when it comes to the sensorial modality, it is imperative to investigate the effects of the five senses, along with proprioception (and even interoception), on the production and reception of an architectural site. The sensorial modality relates to the reception of the final product. After all, many actions must be taken in relation to an edifice's affordances, ${ }^{11}$ such as the opening/closing of doors to enter/exit spaces, or the opening of windows to let light and air in/out. Moreover, regarding touch, the impact of the relative brightness, temperature, and humidity in an edifice will all affect its users. The combination of multiple materials with the natural element-meteorological conditions-allied to the human activities happening inside the edifice, will produce aromas and odors which are likely to affect the sense of smell. One example might be the smell of food that recurrently comes from the kitchen and is permanently absorbed by the living-room carpet. Hearing is also affected by the combination of the chosen materials, the weather, and human activities: for example when the sound of rain on a tin roof hinders someone's concentration while studying. The only sense that is not likely to manifest in an architectural process is taste. However, regarding its connotative meaning, taste, as in aesthetics, should also be considered. For Paul Crowther, "the building's articulation of form, shape, and mass in enduring materials, on the basis of symmetry, proportion, and the like, offers a kind of rectification or idealization of the body's vectors of sensorimotor activity" (Crowther 2009: 181-author's emphasis). Although not as deeply scrutinized as the five senses, along with mental introspection and interoception, the relevance of proprioception is brought about in the expanded model for understanding intermedial relations (Elleström 2020: 27, 30, 49). The kinesthetic sense, in particular the sensorimotor activities, must be included when it comes to the investigation of architecture's sensorial modes. As underscored by Arnheim, all these sensorial experiences depend on the historical, social, and even personal context. In sum, an architectural site can virtually activate all senses at once.

Given that "spatiotemporal modality is a category of spatiotemporal media modes" and media products "consist of physical matter", their spatiotemporal properties can "be grasped by human minds" (Elleström 2020: 48). An architectural process definitively occupies different types of spaces which cannot be dissociated from time. In spite of being known as the art of creating space, it is perhaps more accurate to say that architecture alters and organizes space. Unsurprisingly, space and time are among the comparative aspects most frequently studied by both architectural and 
literary scholars. Rasmussen argues that the relationship between space and time is among the greatest difficulties faced by any architect whose "work is intended to live on into a distant future". The professional "sets the stage for a long, slowmoving performance which must be adaptable enough to accommodate unforeseen improvisations" in an edifice which "should preferably be ahead of its time when planned so that it will be in keeping with the times as long as it stands" (Rasmussen 1964: 12). For him, "one of the proofs of good architecture" lies in buildings whose space "is being utilized as the architect had planned" throughout time (Rasmussen 1964: 12).

In architecture, communication and human experience do not endure virtually, as in literature; they happen, effectively, within a materialized space. In contrast with literature and cinema, which can be preserved through technical, digital, or virtual reproduction, an edifice never reaches the status of final product, since its materiality will always be vulnerable to climatic and socioeconomic variations. Another noteworthy aspect of the spatiotemporal modality is the ratio between the final product's volume, depth, and height, as considered by Stephanie Glaser in her latest works (2014, in press).

In order to provide stability to the piers, besides the understanding of architecture's four modalities, special attention should be given to the origins, delimitations, and usage within the specific historical, cultural, and social circumstances of both production and reception of the investigated architectural environments in relation to their aesthetic and communicative features, as in the qualifying and operational aspects suggested by Elleström's model (2020). This investigation leads to the fact that, due to the matter of form and function, including the study of ergonomics and affordances of architectural elements, the scale of an edifice is set by the human body. Thus, two more notions inherent to architecture should be taken into consideration in order to tangibly delve into its modes: embodiment and perspective.

\subsection{Adding Girders: Embodiment and Perspective}

In section two, I discussed how the modes of architecture both operate throughout its process and compose its final media product. Since its materiality is also manifested at the virtual level, the semiotic mode may be indicated not only by possible structural similarities and diagrammatic forms of representation evidence, but mainly by verbal negotiation in 
assigning meaning along the architectural process as a whole. By delving into the presemiotic modes, I realized the indissoluble three-dimensional space and time in relation to the building, and the role of affordance and ergonomy within aesthetic matters of the studied edifice. After all, since ancient times, architecture has relied on the human body as both metaphor and unit of measurement (Spurr 2012: 36). Yet the interaction of the user with architectural environments through the senses, including proprioception, makes the notion of embodiment indispensable to set a backbone for the architectural traits most easily transferred to literature. At the same time, the points of intersection of the different connotations of the notion of perspective in different disciplines - architecture, art history, and literature-must also be taken into account.

The understanding of how subject and object, in opposition to Cartesian dualism, comprise two facets of a single unit is fundamental to further investigations of architecture as a process. The concept of embodiment proposed by Maurice Merleau-Ponty (1945) sustains not only the inextricability of body and mind, but also the awareness of the perception and representation of the world (Auslander 2008: 136-139). Embodiment is used as a basis for performance studies when dealing with stage experience by the actors and its perception by the spectators. As previously mentioned, architects Émile Aillaud and Steen Rasmussen established, in two distinct historical moments, the analogy of the building as stage. Chiel Kattenbelt (2006), in a similar line of reasoning, uses the term "corporeality" to designate the effect of the actor's body onstage as in the materiality of that body in the theatrical space. This idea recalls the proposed discussion of how the body of a dancer may act as both technical medium and media product, as when Elleström quotes the famous question posed by Yeats- "How can we know the dancer from the dance?"-in the introductory chapter of this volume $(2020: 36)$. Nonetheless, in the case of architecture, the focus should not be on distinguishing the architect from the edifice, but on determining how anyone can actually experience kinesthetically the three-dimensionality of its final media product. That is to say, even if this process initially relies on concepts and transfer of mental cognitive import between client, architect, and other professionals, in order for any edifice to be considered architecture, as opposed to a piece of sculpture, it must eventually be experienced by the bodies of final users.

In an attempt to advance relevant aesthetic and ethical discourses within architectural theory, Åsa Dahlin (2002) highlights that it is not enough to (re)cognize architecture's material aspects. For her, reason and emotion, 
much like mind and body, should not be treated as oppositions, but as parts of the same system. It is therefore necessary to consider knowledge generated by humans' physical as well as mental consciousness. Sophia Psarra (2009), in turn, is concerned with the way theoretical focus on the visual perception of form has shifted to the embodied experimentation of space (13), which guided her methods for investigating the interfaces between conceptual and perceptual facets of an architectural project to be based on the notion of embodied experience. In sum, embodiment-as in proprioception, be it from a spatiotemporal and sensorial understanding, or from a philosophical standpoint-is relevant when showing the effect of the user's body within an architectural environment.

While Rasmussen states that "it is not enough to see architecture; you must experience it $[\ldots]$ you must dwell in the rooms, feel how they close about you, observe how you are naturally led from one to the other" (Rasmussen 1964: 33), Arnheim calls attention to the fact that optical images are projected in two dimensions by the human eye, so the brain does fully grasp a three-dimensional object just from one stand point (Arnheim 1977: 110). To provide a more concrete example, the way in which "we may change our position deliberately to gain a more comprehensive view" (110) can be illustrated by the renowned passage from Marcel Proust's In Search of Lost Time in which the narrator observes "three clock towers that change their relative position" (118-119). According to Arnheim, in this scene, Proust anticipates the cinematic technique of traveling, which is related to periegesis, an ancient rhetorical tool employed in the description of places, landscapes, and buildings (see Glaser in press). Accordingly, Rasmussen suggests that users' perception of different standpoints is enabled by walking around and within an architectural site. So even if perspective deforms the object or tricks the eye, the human mind still "organizes, completes and synthesizes the structure" such that the three-dimensional object "will be seen spontaneously as a whole" (Arnheim 1977: 110). The acknowledgment of the timeless existence of an edifice in space in the visitor's architectural experience, along with the peculiarities of the human eye in relation to the mind, heightened my awareness of the relevance of the dialogue between the notions of embodiment and perspective. As previewed, I now present how the different facets of the notion of perspective affect architecture's medial traits to be presented by literature.

In architecture studies, even if it is part of a wider discussion of representation at a more technical level, ${ }^{12}$ Alberto Pérez-Gómez and Louise 
Pelletier have claimed that their "ultimate aim is to probe the possibilities of building architecture as a poetic translation, not a prosaic transcription, of its representation" (Pérez-Gómez 1997: 8). The authors have historicized methods of architectural representation since the Renaissance, when the introduction of systematized descriptive geometry significantly shifted the terms between the architectural process and its final product (PérezGómez and Pelletier 1992: 22-37). Another major shift in the role of perspective within the architectural process was promoted by the consciousness of the observer as the organizer of a composition (Pérez-Gómez 1997: 19). In the same vein, Karsten Harries calls attention to the way architecture "relies on imitation" (1997: 112) as do other art forms. These theorists' discussion of the evolution of forms of representation has contributed to my own understanding of the difference between architectural technical representation by means of perspective, as well as the notion of mimetic representation prevalent in traditional ekphrastic studies.

The origin of the term perspective in art history and the history of science derives from either Arabic geometry (i.e. math) or western perception (i.e. aesthetic theory) (Belting 2011: 1-2). Math plays an important part in painting and architecture, which is not necessarily true for literary studies. Despite being "unoccupiable" (10), the vanishing point of classic perspective in painting allows spectators to objectify themselves externally from a given image, which, in turn, delivers a deictic proclamation from a particular location, in a specific moment in time. The dynamic caused by perspective in paintings allows viewers to be positioned in places in which they have never physically been; in other words, presence and absence are intertwined in an indissoluble relationship (10). This relationship established from a vanishing point corroborates my investigation of ekphrasis inspired by architecture.

In the realm of the visual arts, the notion of perspective has changed in the wake of the (still controversial) work of Edwin Panofsky, Perspective as Symbolic Form (1997 [1937]). James Elkins explains how, differently from our current comprehension of the notion of perspective, Renaissance artists and writers conceived of "unchangeable" concepts, such as the idea of pictures being "in perspective". According to him, the greatest shift in the understanding of perspective was departing from its understanding "as a mute method, a practical subset of geometry" and adhering to "a powerful concept for ordering our perception and accounting for our subjectivity" (Elkins 1994: xi). Thus, when it comes to this favoring of its metaphorical understanding and forgetting it as a practice, there are 
inevitable consequences to the way we perceive it in painting, philosophy, literary studies (xi), and architecture. That is, for him, "perspective directs our eyes and orders our thoughts $[\ldots]$ it seems to control not only what I see, but how I see and how I describe what I see" (Elkins 1994: 212). The difficulties of thinking through and around a certain viewpoint arise because, at least for the visual arts, perspective is mostly self-confined. For Elkins, "the modern concept of perspective is schizophrenic, [in a way], because it has two incompatible aspects". The first is the "formal, rigorously defined branch of [math]: the perspective that we trace from Brunelleschi's experiments through the latest software", or today's understanding of the term perspective inside architectural studies. The second aspect "means a great deal, from subjectivity to eternity, and it is to be found virtually everywhere, from philosophy texts to political speeches". Elkins calls this second aspect, not derived from an equation or a graph, the metaphorical perspective. He explains that this "is 'our' perspective, the one we think about, and the one that describes how we view the world and constitute ourselves as viewing subjects" (6). Consequently, this claim for an exclusive individual point of view, as proposed by visual art theorists, is likely to engage with the notion of focalization as articulated by narratology studies.

The narratologist Gérard Genette (1972) acknowledged the terms "perspective" and "point of view" as synonyms and coined the term "focalization" as a replacement for both. Grounded on the premises suggested by Genette, Tamar Yacobi (2002) points out that perspective has revolutionized both the theory and the practice of European painting since the Renaissance, activating lines of communication that bring artist and spectator closer together. Likewise, both Liliane Louvel (2010) and Stephanie Glaser (2014) consider the narrator's focalization in ekphrastic passages dealing with architecture. According to Louvel, by offering both aesthetic and artistic context, the visual information brings additional clarity to the literary text. She states that, differently from painting, the presence of architecture in literature deals with the passage from architecture's three-dimensional space to the two dimensions of the literary object. She illustrates this argument with the opening of Wuthering Heights, in which a trompe-l'oeil effect reveals a labyrinthine space concealing the plot's secrets (Louvel 2010: 118-120). Accordingly, the house's façade, as focalized by Lockwood's character, is treated by Louvel as a historized page of its residents' lives. Glaser in turn bases her proposal on the notion of focalization suggested by Genette and revisited by Mieke Bal. ${ }^{13}$ For Glaser, the 
ekphrasis of an architectural site may deepen the narrative or become attached to it on a thematic level (Glaser 2014: 13-15). For me, this process of verbally presenting architecture is likely to engage the narrator's gaze in a way that implies not only the observer's physical position in relation to the architectural space-the literary persona's focalization-but also their eye movement.

Aiming at incorporating focalization and other types of perspective present in spatial descriptions from nineteenth- and twentieth-century novels (nouveau roman included), the narratologist Monika Fludernik (2014) developed a typology based on a model for the triple distinction of perspective, used by Holly Taylor and Barbara Tversky in their studies of cognitive linguistics (1996). According to these authors, when describing a space or a place, a speaker can guide the addressee on a mental tour from three different perspectives: (a) the survey, (b) the gaze, and (c) the route. The survey perspective is neutral, like an aerial view. The use of deictic terms is avoided in this type of description, which favors the universal lexicon of orientation (North, South, East, West). This, according to Taylor and Tversky, is most common in literary descriptions, tourism guides, and textbooks. From the narrator's perspective, or from a route perspective, the observer is inserted into the narrated space. In type (b), the description, the observer stands on a fixed location and makes use primarily of stative verbs. Finally, in type (c), by favoring action verbs, the observer traverses the environment (Taylor and Tversky 1996: 371-376). With the goal of broadening this model within the context of narratology, Fludernik combines types (b) and (c) into a single category and creates subdivisions in order to demonstrate that spatial descriptions are not necessarily confined to the extradiegetic level (Fludernik 2014: 472-474). In sum, the focalization of the (ekphrastic) passages will fill functional gaps within the plot of a literary text, and the many facets of perspective will be revealed through literary descriptions of spaces, places, and buildings - that is, of architectural ekphrasis.

Although focalization and perspectivism do not necessarily coincide, both bring about the relevance of the observer's consciousness and embodiment as the organizer of verbal compositions. I therefore propose to add the notion of embodiment and to stretch the limits of perspective and focalization as girders in determining exactly which architectural modes may be successfully revealed by works of fiction. 


\subsection{The Deck, or Architecture's Medial Traits}

This realization that architecture's modalities and its design process may be conveyed by words led me to the understanding of the actual modes that may be feasibly transmediated to literature. The parameters were set by combining Elleström's proposed model for studying the transfer of media characteristics between dissimilar media to the notions of embodiment and perspective, namely (a) the appeal to the senses, likely to be revealed through the user's bodily interaction with the building; (b) the employed lexis, based on the materiality revealed at the physical level, through materials such as concrete and glass, and the virtual level, through what lies in both clients' and architects' minds; (c) language functions; (d) citations of architects' and edifices' names and titles; (e) meaningful repetitions; (f) possible structural similarities and the importance of diagrammatic forms of representation; $(\mathrm{g})$ verbal negotiation in assigning meaning over the course of the architectural process; $(\mathrm{h})$ the indissoluble spacetime relation in man-made environments, marked by deictic indicators; (i) the three-dimensionality of space, as proven by the ratios between height, length, and depth; ( $j$ ) the role of affordance and ergonomy in relation to aesthetics; $(\mathrm{k})$ the dynamics of perspective, focalization of the excerpt in question, and the literary persona's position in relation to the vanishing point, which will guide the receiver's eyes; and, finally, (l) the intercrossing of all the aforementioned evidence with historical, cultural, and social contextualization of the architectural process as well as the positioning of client, architect, and final users. These parameters provided the deck for my proposal of an interpretative model for architectural ekphrasis that encompasses four horizontal and non-hierarchical typologies: technical, symbolic, contemplative, and performative. ${ }^{14}$

The inherent potential to store information throughout an architectural process, from its inception to the edifice per se, guarantees its status as a medium. Developed in a dynamic communicative process, each stage of its design is fulfilled through specific qualified submedia (sketches, plans, blueprints, mockups, CG renderings, and 3D models), all of which require prior technical knowledge. In this case, both semiotic and material modalities play equally important roles within the transfer of medial traits. Conversely, when the beholder's cultural background knowledge is at stake, the semiotic modality prevails. I understand these two types of procedures as technical and symbolic, respectively. 
There are cases in literature wherein characters contemplate architectural environments, buildings, or even urban landscapes from a specific point of view, without the focalizing agent physically interacting with the focalized architectural site. In such cases, the transmediation of architecture may borrow medial traits from other media, such as painting, photography, or sculpture. Here the notion of perspective plays a highly relevant role, since it is the focalizer's relation to the architectural site that will determine its contemplative nature. Architecture is treated as a twodimensional medial configuration in cases where the focalizing agents behave as if they were in an art gallery. Meanwhile, when an architectural site is admired in its three-dimensional totality—as suggested by Aillaud, Rasmussen, and Kattenbelt - the focalizer behaves as if in a theatrical play and the edifice is likewise treated as a stage. Since embodiment plays a crucial role in the understanding of architecture as both process and media product, one may identify passages in which the observer, be it the narrator or a character, takes full advantage of the architectural medialities presented thus far. In such cases, all modalities, along with embodiment, have an impact on the characters' performative actions while touring an architectural site-going up and down, in, out, and around it. The reader ceases to be a mere spectator and becomes involved in a virtual performance. In sum, since only a limited number of architecture's medial traits can be satisfactorily transmediated by literature, the model here proposed by Elleström was crucial not only to delimit its modality modes, but mainly to bridge architecture to literature.

\section{Notes}

1. Original text: "o ponto de encontro das ciências exatas e do humanismo" (Biselli apud Penna 2005: np). Unless otherwise stated, all translations are my own in collaboration with Maria Viana.

2. Original text: "o espaço-síntese de toda a cultura" (Penna 2005: np).

3. Original text: "arte e técnica de organizar espaços e criar ambientes para abrigar os diversos tipos de atividades humanas, visando também a determinada intenção plástica" (Houaiss and Villar 2009: 186). This definition is from a Brazilian Portuguese dictionary. I tried to find a similar definition in an English dictionary, but since the closest I got was "the art and practice of planning and designing buildings" (Longman Dictionary 1995: 56), I chose to translate the more thorough definition that expresses what I have in mind. 
4. Patrik Schumacher (1961-) is the director of the firm founded by renowned architect Zara Hadid (1950-2016).

5. For more on architectural ekphrasis, see Vieira (2020, in press).

6. Please note that self-buildings and unplanned construction "on the spot" do not necessarily undergo the sort of professionalized architectural process on which my investigation is grounded.

7. These would traditionally mean sketches and presentation drawingshowever, given the current predominance of architectural software, digital correspondents have now substituted the handmade graphic submedia that previously constituted this stage.

8. These submedia are analogous to the playscript of a theatrical production, since it can also be understood individually. Often, the computer graphic renderings, or three-dimensional models, mark the end of the process in the development of an architectural work, as in schools of architecture, or when the client terminates a contract due to financial limitations. Even if the process continues, this is often the point where the architect's work ends. The architect can continue to follow the process during its technical stage, usually carried out with the aid of engineers, or during construction, but it is not obligatory.

9. These are initially developed according to local norms and legislation and, once approved by the due authorities, reworked to account for issues of engineering.

10. Philippe Hamon (1999) proposes a model to investigate the mutual fascination regarding the use of architecture in nineteenth-century French literature. In this model, he establishes four reciprocal aspects-namely metalinguistic, semiotic, architectural representation, and historical context.

11. The term affordance describes a given object's potential as suggested by its configuration, planned beforehand by a designer and manifested when an agent operates it in accordance with its structure. For example, a round doorknob encourages the agent to turn it. For more on this, see Gibson (1986).

12. In the age of digital technology, the discussion still remains technical. With the introduction of computer tools at the end of the twentieth century, manual graphic representation became digital. Computer resources and software used in the elaboration of three-dimensional models, which have replaced artistic perspective drawings, may now produce architectural renderings so realistic that viewers are often unable to distinguish them from "real" (i.e. photographic) images.

13. Gérard Genette (1972) proposes three types of focalization: zero, internal, and external. Mieke Bal (1985) revisits this categorization and suggests a binary system, composed only of the internal and external focalizations. 
According to her, the type zero must be combined with the external, since it speaks not of the observer, but of the observed object.

14. This model is more thoroughly presented in my doctoral dissertation (Vieira 2016). Its core has been compiled in Vieira (in press).

\section{REFERENCES}

Arnheim, Rudolf. 1977. The Dynamics of Architectural Form. Berkeley: University of California Press.

Auslander, Philip. 2008. Theory for Performance Studies. New York: Routledge.

Bachelard, Gaston. 1994 (1964). The Poetics of Space. Trans. Maria Jolas. Boston: Beacon Press.

Bal, Mieke. 1985. Narratology: Introduction to the Theory of Narrative. Trans. Christine van Boheemen. Toronto: University of Toronto Press.

Belting, Hans. 2011. Florence and Baghdad: Renaissance Art and Arab Science. Trans. Deborah Lucas Schneider. Cambridge: The Belknap Press of Harvard University Press.

Bloomer, Jennifer. 1993. Architecture and the Text: The (S)crypts of Joyce and Piranesi. New Haven: Yale University Press.

Bruhn, Jørgen. 2016. Intermediality and Narrative Literature: Medialities Matter. Basingstoke: Palgrave Macmillan.

Crowther, Paul. 2009. Phenomenology of the Visual Arts (Even the Frame). Stanford: Stanford University Press.

Dahlin, Åsa. 2002. On Architecture, Aesthetic Experience and the Embodied Mind: Seven Essays. Trans. Kristin Pålsson. Stockholm: School of Architecture, Royal Institute of Technology.

Elkins, James. 1994. The Poetics of Perspective. Ithaca: Cornell University Press.

Elleström, Lars, ed. 2010. Media Borders, Multimodality and Intermediality. Basingstoke: Palgrave Macmillan.

- 2014. Media Transformation: The Transfer of Media Characteristics Among Media. Basingstoke: Palgrave Macmillan.

- 2018a. A Medium-centered Model of Communication. Semiotica 224: 269-293.

- 2018b. Identifying, Construing, and Bridging Over Media Borders. Scripta Uniandrade 16 (3): 15-30.

- 2020. The Modalities of Media II: An Expanded Model for Understanding Intermedial Relations. In Beyond Media Borders: Intermedial Relations among Multimodal Media, Volume 1, ed. Lars Elleström, 3-91. Basingstoke: Palgrave Macmillan.

Fludernik, Monika. 2014. Description and Perspective: The Representation of Interiors. Style 48 (4): 461-478. 
Genette, Gérard. 1972. Discours du récit. In Figures III, ed. Gérard Genette, 67-282. Paris: Editions du Seuil.

Gibson, James J. 1986. The Ecological Approach to Visual Perception. Hillsdale NJ: Lawrence Erlbaum Associates.

Glaser, Stephanie A. 2009. The Gothic Façade in Word and Image: Romantic and Modern Perspectives on Notre-Dame de Paris. In Media inter Media: Essays in Honor of Claus Clüver, ed. Stephanie A. Glaser, 59-94. Amsterdam: Rodopi.

- 2014. Space, Time and Narrative: The Literary Unfolding of Architecture. In Text-Architekturen. Die Baukunst der Literatur, ed. Robert Krause, 13-30. Berlin: De Gruyter.

- in press. Figures of Space, Figures of Time: Gothic Architecture, Enaergeia, and Periegesis. In Making the Absent Present: Challenging Contemporary Concepts of Ekphrasis, ed. Heidrun Führer. Lund: Intermedia Studies Press.

Hamon, Philippe. 1992. Expositions: Literature and Architecture in NineteenthCentury France. Trans. Katia Sainson-Frank and Lisa Maguire. Berkeley: University of California Press.

- 1999. Littérature et architecture. Divisions et distinctions. Quelques généralités. Travaux de Litérature 12: 313-321.

Harries, Karsten. 1997. The Ethical Function of Architecture. Cambridge: MIT Press.

Houaiss, Antonio, and Mauro de Salles Villar. 2009. Dicionário Houaiss da língua portuguesa. Rio de Janeiro: Objetiva.

Kattenbelt, Chiel. 2006. Theatre as the Art of the Performer and the Stage of Intermediality. In Intermediality in Theatre and Performance, ed. Freda Chapple and Chiel Kattenbelt, 29-39. New York: Rodopi.

Longman Dictionary of Contemporary English. 1995. Essex: Longman House.

Louvel, Liliane. 2010. Le tiers pictural: Pour une critique intermédiale. Rennes: Presses Universitaires de Rennes.

Merleau-Ponty, Maurice. 1945. Phénoménologie de la perception. Paris: Gallimard.

Norberg-Schulz, Christian. 1980. Genius Loci: Towards a Phenomenology of Architecture. New York: Rizzoli.

Panofsky, Erwin. 1997 (1937). Perspective as Symbolic Form. Trans. Christopher S. Wood. New York: Zone Books.

Penna, Gustavo. 2005. Arquiteto: Artista, profissional liberal ou empresário? Revista $A U$ 134: np.

Pérez-Gómez, Alberto. 1997. Architectural Representation and the Perspective Hinge. Cambridge MA: MIT Press.

Pérez-Gómez, Alberto, and Louise Pelletier. 1992. Architectural Representation Beyond Perspectivism. Perspecta 27: 21-39.

Pettersson, Ulf. 2013. Textually Mediated Virtual Worlds: Narration, Perception and Cognition. Växjö: Linnaeus University Press.

Psarra, Sophia. 2009. Architecture and Narrative: The Formation of Space and Cultural Meaning. New York: Routledge. 
Rasmussen, Steen E. 1964 (1959). Understanding Architecture. Cambridge MA: MIT Press.

Schumacher, Patrik. 2010. The Autopoiesis of Architecture, Volume I: A New Framework for Architecture. London: John Wiley \& Sons.

- 2011. The Autopoiesis of Architecture. Interview by Loreto Flores. Revista de Arquitectura 23: 1.

Spurr, David. 2012. Architecture and Modern Literature. Ann Harbor: University of Michigan Press.

Taylor, Holly A., and Barbara Tversky. 1996. Perspective in Spatial Descriptions. Journal of Memory and Language 35: 371-391.

Vieira, Miriam de Paiva. 2016. Dimensões da écfrase: A presença da pintura e da arquitetura em romances de artista. Belo Horizonte: Universidade Federal de Minas Gerais.

- 2020. Architectural ekphraseis: Unveiling a Brazilian Wall-less House in Contemporary Fiction. In Transmediations: Media Across Media Borders, ed. Lars Elleström and Niklas Salmose, 118-135. New York: Routledge.

- in press. "Out of space: the complexity of contemplative and performative architectural ekphrasis". In: Text-Image-Music: Crossing the Borders. Intermedial Conversations on the Poetics of Verbal, Visual and Musical Texts. In Honour of Prof. Elżbieta Chrzanowska-Kluczewska, ed. by Andrzej Pawelec, Grzegorz Szpila and Aeddan Shaw. Peter Lang series: Text-Meaning-Context: Cracow Studies in English Language, Literature and Culture.

Yacobi, Tamar. 2002. Ekphrasis and Perspectival Structure. In Cultural Functions of Intermedial Exploration, ed. Erik Hedling and Ulla-Britta Lagerroth, 189-202. Amsterdam: Rodopi.

Open Access This chapter is licensed under the terms of the Creative Commons Attribution 4.0 International License (http://creativecommons.org/licenses/ by $/ 4.0 /$ ), which permits use, sharing, adaptation, distribution and reproduction in any medium or format, as long as you give appropriate credit to the original author(s) and the source, provide a link to the Creative Commons licence and indicate if changes were made.

The images or other third party material in this chapter are included in the chapter's Creative Commons licence, unless indicated otherwise in a credit line to the material. If material is not included in the chapter's Creative Commons licence and your intended use is not permitted by statutory regulation or exceeds the permitted use, you will need to obtain permission directly from the copyright holder.

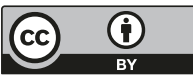

